\title{
Programme evaluation training for health professionals in francophone Africa: process, competence acquisition and use Valéry Ridde*1,2, Pierre Fournier ${ }^{1,2}$, Baya Banza ${ }^{3}$, Caroline Tourigny ${ }^{2}$ and Dieudonné Ouédraogo ${ }^{3}$
}

Address: ${ }^{1}$ Centre de recherche du Centre Hospitalier de l'Université de Montréal, Montréal, Canada, ${ }^{2}$ Department of Social and Preventive Medicine, University of Montreal, Montréal, Canada and ${ }^{3}$ Institut Supérieur des Sciences de la Population, Université de Ouagadougou, Ouagadougou, Burkina Faso

Email: Valéry Ridde* - valery.ridde@umontreal.ca; Pierre Fournier - pierre.fournier@umontreal.ca; Baya Banza - bbaya@issp.bf; Caroline Tourigny - caroline.tourigny@umontreal.ca; Dieudonné Ouédraogo - douedraogo@issp.bf

* Corresponding author

Published: 15 January 2009

Human Resources for Health 2009, 7:3 doi:10.1186/1478-449I-7-3
Received: 15 January 2008

Accepted: 15 January 2009

This article is available from: http://www.human-resources-health.com/content/7/I/3

(c) 2009 Ridde et al; licensee BioMed Central Ltd.

This is an Open Access article distributed under the terms of the Creative Commons Attribution License (http://creativecommons.org/licenses/by/2.0), which permits unrestricted use, distribution, and reproduction in any medium, provided the original work is properly cited.

\begin{abstract}
Background: While evaluation is, in theory, a component of training programmes in health planning, training needs in this area remain significant. Improving health systems necessarily calls for having more professionals who are skilled in evaluation. Thus, the Université de Ouagadougou (Burkina Faso) and the Université de Montréal (Canada) have partnered to establish, in Burkina Faso, a master's-degree programme in population and health with a course in programme evaluation. This article describes the four-week (150-hour) course taken by two cohorts (2005-2006/2006-2007) of health professionals from II francophone African countries. We discuss how the course came to be, its content, its teaching processes and the master's programme results for students.
\end{abstract}

Methods: The conceptual framework was adapted from Kirkpatrick's (1996) four-level evaluation model: reaction, learning, behaviour, results. Reaction was evaluated based on a standardized questionnaire for all the master's courses and lessons. Learning and behaviour competences were assessed by means of a questionnaire (pretest/post-test, one year after) adapted from the work of Stevahn L, King JA, Ghere G, Minnema J: Establishing Essential Competencies for Program Evaluators. Am J Eval 2005, 26(I):43-59. Master's programme effects were tested by comparing the difference in mean scores between times (before, after, one year after) using pretest/ post-test designs. Paired sample tests were used to compare mean scores.

Results: The teaching is skills-based, interactive and participative. Students of the first cohort gave the evaluation course the highest score (4.4/5) for overall satisfaction among the 16 courses (3.4-4.4) in the master's programme. What they most appreciated was that the forms of evaluation were well adapted to the content and format of the learning activities. By the end of the master's programme, both cohorts of students considered that they had greatly improved their mastery of the 60 competences $(p<0.001)$. This level was maintained one year after completing the master's degree, except for reflective practice $(p<0.05)$. Those who had carried out an evaluation in the intervening 12 months reported a negative gap between their declared mastery and their actual application. However, this is only statistically significant for reflective practice $(p<0.05)$.

Conclusion: This study shows the importance of integrating summative evaluation into the learning process. Skills-based teaching is much appreciated and well-adapted. Creating a master's programme in population and health in Africa and providing training in evaluation to high-level health professionals from many countries augurs well for scaling up the practice of evaluation in African health systems. 


\section{Background}

Obtaining international funding in health care is becoming increasingly competitive. For example, to acquire resources needed to fight HIV/AIDS or malaria, African countries must now participate in Global Fund competitions. This situation presents health care managers with two new challenges. First, their requests and action plans increasingly need to be evidence-based. Managers therefore must be able to understand and assess the quality of data and of intervention evaluations. The second challenge is that, when assessing requests, funding agencies look at how well previously-funded programmes met their objectives. These programmes' effectiveness must therefore be demonstrated. Health care managers can no longer be just good planners. They also must be informed evaluators, or have at least the basic knowledge required to interact effectively with the evaluation experts whom they will recruit. Within the current trend of establishing New Public Management in health care in developing countries [1] and the Paris Declaration on Aid Effectiveness [2], programme evaluation will become a major sphere of activity for the coming decade. Yet programme evaluation is rarely addressed in training programmes for health planning [3] and, in Africa, evaluation processes are still too often imposed by external bodies [4].

A series of regional seminars on evaluation planned by the Development Assistance Committee of the Organisation for Economic Co-operation and Development (OECD) was started in 1990 in Côte d'Ivoire [5]. In 1999, the African Evaluation Association (AfrEA) was launched. Despite these efforts, training in programme evaluation remains a relative rarity on the African continent. There are some seminars and workshops, but few training programmes leading to degrees. This is particularly true in francophone Africa $[6,7]$. The strengthening of evaluation capacity building (ECB) has thus become an urgent matter in Africa. Experts in this field are asking for more empirical case studies to document the range of practices in order to improve their knowledge $[8,9]$, as ECB is "an emergent field of practice" [10]. University training is one useful strategy for ECB [11]. A review of articles published in this field between 1965 and 2003 reveals a lack of literature on practical evaluation training [12]. This article presents the evaluation of a course on programme evaluation, a fourweek (150-hour) course attended by health professionals from 11 francophone African countries.

The Université de Ouagadougou (Burkina Faso) and the Université de Montréal (Canada) have partnered to establish, in Burkina Faso, a master's-degree programme in population and health that includes a course in evaluation. This master's programme is part of a larger programme aimed at reinforcing human and institutional capacities in the analysis and evaluation of public policies and programmes. Its goal is to offer a credible alternative to training programmes offered in North America and Europe. The master's-level training programme includes 12 months of course work and a three-month internship (Table 1). The training is organized into modules of several consecutive days, to accommodate the teachers who are brought in from a number of African countries and from Canada.

The overall objective of the master's programme is to develop students' knowledge and aptitudes in analysis, formulation and implementation management, as well as in the evaluation of population and health programmes, including a specific course in programme evaluation (Table 1:3.3). Before presenting the results achieved in the master's programme, we will describe how the course was implemented and its content related to evaluation.

\section{The programme evaluation course: process and content}

The entire content of the master's programme was planned between 2003 and 2004. The organization into modules and the content of each module were decided using a participative process, after an inventory of training programmes in population and health in several francophone African countries [13]. Because the evaluation course integrates all the knowledge and competences acquired in the other courses, it was positioned as the last course taken by students at the end of the 12 months (Table 1). Teaching, when required, would be carried out by African-Canadian pairs, based on the partnership model $[14,15]$. The course content took into account:

- the competences expected of programme evaluators $[16,17] ;$

- the training needs in evaluation in Africa [6,7];

- prior experience of training in evaluation;

- familiarity with training needs of African students.

After this process, the teaching objectives (Fig. 1) and course content (Table 2) were finalized.

The aim is to train professionals who will be able to design, support or carry out a programme evaluation. Students are expected to write an evaluation plan. The course involves 19 lectures or sessions $(9.5 \%$ of total), corresponding to 147 hours of work:

- 52 hours in class in 13 course sessions;

- 52 hours of individual preparatory work;

- 35 hours of group work in preparing evaluations; 
Table I: Structure of the master's programme in 2005-2006

\begin{tabular}{|c|c|c|}
\hline Blocks and modules & Course titles & Number of lessons and \% \\
\hline BLOCK I & Fundamentals and issues in population and health & $31(16 \%)$ \\
\hline Module I.I & Fundamentals & 19 \\
\hline Module 1.2 & Issues & 12 \\
\hline BLOCK 2 & Analysis of population and health issues & $62(31 \%)$ \\
\hline Module 2.1 & Introduction to empirical research methodology & 4 \\
\hline Module 2.2 & Quantitative data sources and basic descriptive statistics & 8 \\
\hline Module 2.3 & Elements of demography and epidemiology & 20 \\
\hline Module 2.4 & Elements of qualitative analysis & 14 \\
\hline Module 2.5 & Introduction to multivariate statistical methods & 16 \\
\hline BLOCK 3 & Analysis of policies and intervention strategies & $48(23 \%)$ \\
\hline Module 3.1 & Fundamentals of public policy analysis & 16 \\
\hline Module 3.2 & Analysis of health systems & 13 \\
\hline Module 3.3 & Evaluation & 19 \\
\hline BLOCK 4 & Communication & $13(7 \%)$ \\
\hline Module 4.I & Communication as a tool for influencing individual and collective health and well-being & 7 \\
\hline Module 4.2 & Advocacy and information management & 6 \\
\hline BLOCK 5 & Planning and implementation of interventions & $47(23 \%)$ \\
\hline Module 5.1 & Principles of planning for interventions & 9 \\
\hline Module 5.2 & Operational planning of interventions (programmes, projects) & 17 \\
\hline Module 5.3 & Implementation of interventions: resource management & 13 \\
\hline Module 5.4 & Monitoring interventions & 8 \\
\hline BLOCK 6 & Internship & (3 months) \\
\hline TOTAL & & 201 \\
\hline
\end{tabular}

- 8 hours of presence for evaluations.

This approach represents a departure from classical teaching methods that generally involve lectures and sometimes directed work. In fact, such methods are rarely effective in training programmes for health personnel in low-income countries [14]. In the case presented here, the entire process is centred on active training in which the student's learning is encouraged, professional experience is validated and course content is more practical than theoretical. Learners actively construct knowledge in collaborative groups [18]. The course uses a myriad of teaching approaches (Table 3 ) based our own experiences as well as well on the literature [19-22], from which some exercises were adapted (see additional files 1 and 2). 
General objective: At the end of this course, students will be able to design a programme evaluation plan, participate actively in carrying out some of its elements, and disseminate the evaluation results.

Intermediate objectives:

1. To know the different stages of planning and implementing a programme evaluation;

2. To be able to describe the logic of a programme and its various elements;

3. To comprehend the ethical and professional issues related to programme evaluation;

4. To be able to analyse the issues around implementation and effects/impacts and to formulate the appropriate evaluation questions;

5. To choose and operationalize an evaluation design that will make it possible to respond to the analysis questions on implementation and effects/impacts;

6. To know the methods for evaluating programme efficiency;

7. To be able to develop different strategies to support the use of programme evaluation results.

\section{Figure I}

Course objectives.

Methods for evaluating students provide an opportunity to improve their knowledge and competences in a twostep learning process. First, a formative evaluation $(20 \%$ of the final course grade) is organized after the first four lessons of the course (Table 2), which constitute a general introduction to programme evaluation. At the end of this first block, groups of four students are given a day-and-ahalf to prepare an oral presentation of a draft evaluation plan. Each team receives the plan for a Burkina Faso health district (a real case), selects a specific theme (AIDS, maternal health, etc.), and then develops and presents the draft of its evaluation plan. This presentation allows the teachers to verify the level of understanding of concepts and whether the evaluation plan is on track. Before the presentation, students also have several occasions to receive feedback on their learning.

Later, a summative evaluation ( $80 \%$ of the final grade) takes place at the end of the course. Communication skills are also evaluated. Students are expected to write a complete evaluation plan based on the elements presented in Fig. 2.

Knowledge acquired in the course is thus integrated in this final project, which is presented orally. Peers have the opportunity to ask questions and give feedback on their colleagues' work. Students are given four days to carry out this project, during which each group has two one-hour consultation sessions with the teacher.

We present here the results of the course evaluations, as well as those related to competence acquisition among the two first student cohorts (Cohort 1: 2005-2006; Cohort 2: 2006-2007) at the end of the master's training.

\section{Methods}

\section{Conceptual framework}

We used a conceptual framework that bases programme evaluation on four levels of outcomes [23]:

- Level 1: Reaction = participants' satisfaction;

- Level 2: Learning = participants' knowledge acquisition, improved skills or changes in attitude;

- Level 3: Behaviour = changes in participants' on-the-job behaviour;

- Level 4: Results = final change at the organizational and population levels.

Our discussion here is limited to levels 1 to 3 .

\section{Data collection tools \\ Reaction}

At the end of each session and course, every student of Cohort 1 completed a standardized questionnaire containing nine closed questions (Likert-type scale of 1 to 5) and one or two open questions.

Learning

We used a standardized questionnaire adapted from the taxonomy of essential competences for programme evaluators $[16,17,24]$. This taxonomy is a list of 60 competences clustered into six major categories (see Fig. 3), translated into French. As is often the case for this type of evaluation [25], it was impossible to do a pretest before the course because most of the vocabulary was unfamiliar to students. Thus, as has been recommended $[25,26]$, we 
Table 2: Lessons of the programme evaluation course for Cohort I

\begin{tabular}{|c|c|}
\hline Lesson 3.3.1 & Introduction and overall process for evaluation \\
\hline Lesson 3.3.2 & Types and approaches to evaluation \\
\hline Lesson 3.3.3 & Intervention logic \\
\hline \multirow[t]{2}{*}{ Lesson 3.3.4 } & Standards and practices in evaluation \\
\hline & Formative evaluation \\
\hline Lesson 3.3 .5 & Implementation analysis I (conceptual bases) \\
\hline Lesson 3.3.6 & Implementation analysis 2 (case study: step I) \\
\hline Lesson 3.3.7 & Implementation analysis 3 (case study: step 2) \\
\hline Lesson 3.3.8 & Analysis of effects/impact I (causal attribution) \\
\hline Lesson 3.3.9 & Evaluation design I: principles and practices \\
\hline Lesson 3.3.10 & Evaluation design 2 (case study: step 3) \\
\hline Lesson 3.3.11 & Efficiency I \\
\hline Lesson 3.3.12 & Efficiency 2 \\
\hline Lesson 3.3.13 & Utilization of evaluation results \\
\hline Lesson 3.3.14 & Group work and consultation sessions \\
\hline Lesson 3.3.15 & Group work \\
\hline Lesson 3.3.16 & Group work and consultation sessions \\
\hline \multirow[t]{2}{*}{ Lesson 3.3.17 } & Group work \\
\hline & Summative evaluation \\
\hline
\end{tabular}

used a retrospective pretest and post-test. The test was administered at the end of the evaluation course, which also corresponds to the end of the master's programme. In addition, for the first cohort of students ( $\mathrm{n}=17)$, a second post-test was administered one year later. For each competence, students were asked to assess, on a Likert-type scale of 1 to 4 (easily ... not at all), their degree of mastery before ("I was able to...") and after ("I am able to...") the master's programme.

\section{Behavior}

By means of the same questionnaire as for competences, we asked students of Cohort 1 whether they had used them (Likert-type scale of 1 to 4 (easily ... not at all)).

\section{Data analysis}

Programme effects were tested by comparing differences in mean scores between times (before, after, one year after) by pretest-post-test design. Paired sample tests were used to compare mean scores. Data analyses were carried out with $\mathrm{SPSS}^{\circ}$.

\section{Results \\ Participants}

Cohort 1 consisted of 17 students: nine men and eight women, from eight West African countries. Cohort 2 was made up of 19 students: 11 men and eight women, from 11 countries. These students come from a wide variety of disciplines: medicine (13), sociology (10), psychology (2), geography/development (5), pharmacy (3), statistics (1), demographics (1) and nutrition (1).

\section{Trainees' reaction}

The evaluation by Cohort 1 of the content of each of the 16 modules of the master's programme is presented in the Additional file 3. Additional file 4 presents the results of the evaluations of each lesson (Table 2) of the evaluation course.

\section{Trainees' learning}

Both cohorts felt they had greatly improved their mastery of the 60 competences by the end of the master's programme. The differences were all positive and all statistically significant for each of the competences (Additional file 5) and for five of the six clusters (Table 4). For both cohorts, the smallest gain was in interpersonal competences, but the level for this before the course was already among the highest (Fig. 3). On the other hand, reflective practice grew substantially in both cohorts.

Among the 10 competences showing the greatest progression, the four that were common to both cohorts were related to the systematic inquiry cluster (2.6: "specifies programme theory"; 2.8 : "develops evaluation designs") and reflective practice (5.3: "pursues professional development in evaluation"; 5.5: "builds professional relationships to enhance evaluation practice"). Among the 10 competences remaining at the lowest level, the five common to both cohorts were related to the systematic inquiry cluster (2.11: "assesses validity of data"; 2.20 : "conducts meta-evaluations"); situation analysis (3.5: "addresses conflicts") and project management (4.1: "responds to requests for proposals"; 4.3: "writes formal agreements").

One year after the end of the master's programme, students of Cohort 1 felt that their level of knowledge had been maintained overall, with the exception of reflective practice (Table 4). Detailed analysis of the 60 competences shows a decrease in mastery of five competences after a year (see additional file 3): 4.2 "presents work in a timely manner"; 5.3 "pursues professional development in evaluation"; 5.4 "pursues professional development in relevant content areas"; 5.5 "builds professional relation- 
Table 3: Examples of pedagogical techniques

\begin{tabular}{|c|c|c|}
\hline Technique & Content & Description \\
\hline Simulation & Ethical dilemma of negotiation with a client & $\begin{array}{l}\text { A client asks an evaluator to change his evaluation design to please a funding } \\
\text { agency. Two groups of students receive the same case description; one is in } \\
\text { favor of the request, and the other against. }\end{array}$ \\
\hline Drawing & Definition of the evaluation & $\begin{array}{l}\text { Each student must produce a drawing representing his or her perception of } \\
\text { the evaluation (see additional file I) }\end{array}$ \\
\hline & Logic model & $\begin{array}{l}\text { Each team of students must prepare a graphic representation of the } \\
\text { constituent elements of a programme's logic (see additional file } 2 \text { ) }\end{array}$ \\
\hline Case study & Theory of intervention & $\begin{array}{l}\text { Each team must determine the theory of the intervention with its various } \\
\text { components based upon a real case: the referral system for obstetrical } \\
\text { emergencies at Kayes in Mali. }\end{array}$ \\
\hline Problem-based learning & Evaluation plan & $\begin{array}{l}\text { Each team must draw up an evaluation plan for a health district in Burkina } \\
\text { Faso. }\end{array}$ \\
\hline Debate & Evaluation profession & $\begin{array}{l}\text { A senior public health consultant is invited to discuss with the class the } \\
\text { profession in Africa. Students must prepare questions in advance. }\end{array}$ \\
\hline
\end{tabular}

ships to enhance evaluation practice"; 6.6 "demonstrates cross-cultural competence". Three of these competences are located in cluster 5 (reflective practice).

\section{Trainees' behaviours}

Among the 15 students of Cohort 1 who responded to the questionnaire a year later, eight (53\%) had carried out evaluations, four (26\%) had participated in evaluations, and three $(20 \%)$ had commissioned evaluations. Students who reported having put their knowledge into practice over the intervening 12 months observed a negative gap between their declared mastery and their actual practice (Table 4, Fig. 3). However, this is statistically significant only for reflective practice. A close look at all 60 compe-
1. Summary
2. Introduction
3. Context for the programme and its evaluation
4. Theme selected from the district plan for evaluation
5. Stakeholders and issues related to the evaluation
6. Logic of the intervention
7. Type of evaluation and details on the evaluation questions
8. Evaluation approaches
9. Proposed process for meeting practice standards
10. Evaluation design (design, data, tools, analysis methods)
11. Process for communicating results
12. Proposed strategy for utilization of the results
13. Conclusion
14. Bibliography
15. Appendices: schedule, budget, distribution of roles/responsibilities among team members

\section{Figure 2}

\section{Contents of an evaluation plan.}




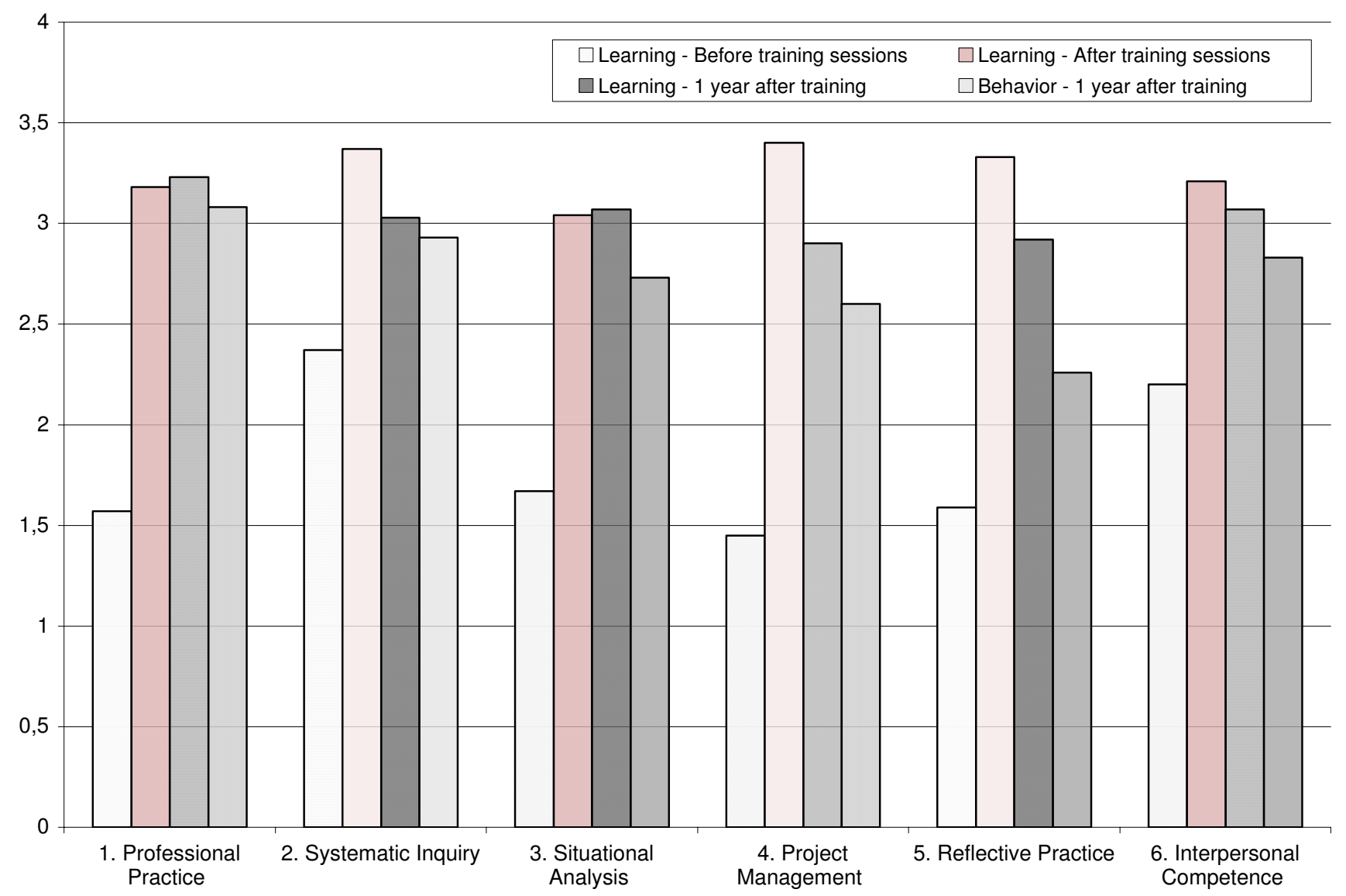

Figure 3

Mean score for competences cluster for Cohort I only.

tences reveals that the situation is the same for 40 of them, where there is a negative gap between declared mastery and actual practice. However, this gap is statistically significant for only two competences: 3.2 : "determines programme evaluability", and 5.1: "aware of self as an evaluator" (see additional file 3).

\section{Discussion}

A number of methodological limitations to the reported results should be mentioned. First, while our assessment was exhaustive, our sample sizes were small, and thus it is quite possible that the difference between behaviour and learning for Cohort 1 is not statistically significant $(\mathrm{n}=8$ or 7). Second, with respect to the tools, it is possible that a fatigue bias was introduced into the results of the evaluation of all the lessons and courses of Cohort 1. In the African context, where students are rarely asked to evaluate courses and teachers [27], a social desirability bias could also have been introduced. However, if this was the case, it would be true for all the courses and not only for the one described in this article. In addition, we believe we chose the proper instrument because "more than three decades of research on post + retrospective pretest method has unequivocally supported this approach" [25].

Our analysis of the teaching of programme evaluation using the process described above shows that not only was it much appreciated by the students but it also produced positive outcomes. The students gained much knowledge and the degree of mastery of competences was increased and maintained over time. The greatest progress was in competences that were very specific to programme evaluation, as opposed to those in which the students already had attained high levels (systematic inquiry and interpersonal competence). It should nevertheless be noted that the positive effects cannot be attributed solely to the evaluation course, since many other courses in the programme also reinforced certain competences that were on the list of 60 . The effect, then, is that of the programme as a whole, which is not a master's degree in evaluation, but rather in population and health. The competences in which the students rated low at the end of the programme were in fact elements that were not addressed in the evaluation course or in the master's programme. That being 
Table 4: Differences in mean scores between points in time for competence clusters

\begin{tabular}{|c|c|c|c|c|}
\hline \multirow[t]{4}{*}{ Cluster of competences } & \multirow{2}{*}{\multicolumn{2}{|c|}{$\begin{array}{c}\text { Learning } \\
\text { After versus Before }\end{array}$}} & \multicolumn{2}{|c|}{ Behaviour versus Learning } \\
\hline & & & \multirow{2}{*}{$\begin{array}{l}\text { I year After versus After } \\
\text { Cohort I }(\mathrm{N}=17)\end{array}$} & \multirow{2}{*}{$\begin{array}{c}\text { I year After } \\
\text { Cohort I }(\mathrm{N}=8)\end{array}$} \\
\hline & Cohort I $(N=17)$ & Cohort $2(N=19)$ & & \\
\hline & Mean & Mean & Mean & Mean \\
\hline I. Professional practice & $1.6 I^{* * *}$ & $1.67^{* * *}$ & 0.05 & -0.25 \\
\hline 2. Systematic inquiry & 1.00 & $1.20 * * *$ & -0.35 & -0.11 \\
\hline 3. Situational analysis & $1.36^{* * *}$ & $1.54^{* * * *}$ & 0.02 & -0.34 \\
\hline 4. Project management & $1.95 * *$ & $1.75^{* * * *}$ & -0.51 & -0.33 \\
\hline 5. Reflective practice & $1.74^{* * * *}$ & $1.99 * * *$ & $-0.42 *$ & $-0.4 I^{*}$ \\
\hline 6. Interpersonal competence & 1.01 **** & $0.97^{* * * *}$ & -0.15 & -0.17 \\
\hline
\end{tabular}

Note: ${ }^{*} \mathrm{p}<0.05 ; * * \mathrm{p}<0.01 ; * * * \mathrm{p}<0.001$

said, students' low rating of the evaluation of data validity (2.11) should certainly be addressed rapidly by those responsible for the programme.

This double positive effect is definitely attributable in part to the skills-based teaching approach. The training in programme evaluation remained practical, dynamic and respectful of the students. This was not surprising, since most teachers in evaluation espouse this type of interactive teaching $[3,12,18,21]$, which was also observed during an experience in Mali [28]. Rapid integration of the concepts into concrete exercises was an effective strategy, as was the availability of the teaching staff during the lessons. The fact that the difference in knowledge acquisition after the course in the "systematic inquiry" cluster (Table 4) was not statistically significant for Cohort 1 can be explained by: (1) a very elevated pre-course self-evaluation (2.37); (2) a selection of students who had already acquired competences in their training prior to the master's programme; and (3) competences that were interdisciplinary.

With respect to level 3 (learning), the data show that it is more difficult to implement evaluation skills than to understand them. In addition, reflective practice remains the only cluster in which the reduction is statistically significant for levels 2 and 3 one year later, while improvements at the end of the master's programme were the highest (Table 4). Thus, the students learned from this perspective, but it is clear that for them, as for all health professionals [29], reflecting in action is not the easiest thing to do. Many skills cannot be sustainably acquired in a university programme; if evaluators' skills are to improve, they must be put into practice. Also, our results suggest the importance of organizing the field of practice in evaluation with the help, for example, of the AfrEA, which could propose continuing education programmes and support reflective practice.

With regard to modalities for evaluating the students' learning, this study shows the importance of integrating summative evaluation into the learning process. From the beginning of the course, students knew the course content, how they would be evaluated at the end, and on what criteria. Transparency was essential. However, the most helpful aspect was that the knowledge and skills considered indispensable for developing an evaluation plan (as an instrument for evaluating learning) were evaluated (through practical exercises) throughout the course.

The tool for assessing evaluation competences has rarely been used, except by its creator [24]. In this case, we found it very useful for understanding the strengths and weaknesses of the teaching provided. It allowed us to measure the level of students' knowledge as well as those elements where there was still work to be done. However, this tool was developed in North America, and the question of whether African evaluators might not need other specific competences remains to be examined.

\section{Conclusion}

This study shows that skills-based teaching is feasible, much appreciated and well-adapted for a university-based evaluation training programme in a West African context. We highlight the importance of integrating summative evaluation into the learning process. Creating a master'sdegree programme in population and health in Africa and providing training in evaluation to high-level health pro- 
fessionals from many countries augurs well for scaling up the practice of evaluation in African health systems. However, this cannot occur without significant investment being made across Africa to develop university-based and professional courses in programme evaluation.

\section{Competing interests}

The authors declare that they have no competing interests.

\section{Authors' contributions}

VR led the study, data collection and analysis, and wrote the first draft. All authors contributed to the study's conception and design and reviewed the final draft. CT did the statistical analysis. VR is a research fellow with the Fonds pour la Recherche en Santé du Québec (FRSQ).

\section{Additional material}

\section{Additional file 1}

Drawing the perception of an evaluation (photo). Each student must produce a drawing representing his or her perception of the evaluation. Click here for file

[http://www.biomedcentral.com/content/supplementary/14784491-7-3-S1.png]

\section{Additional file 2}

Graphic representation of the logic of an intervention (photo). Each team of students must prepare a graphic representation of the constituent elements of a programme's logic.

Click here for file

[http://www.biomedcentral.com/content/supplementary/14784491-7-3-S2.png]

\section{Additional file 3}

Evaluation of the content of each module by the students of Cohort 1 $(n=17)$. Results of the evaluation by Cohort 1 of the content of each of the 16 modules of the master's programme.

Click here for file

[http://www.biomedcentral.com/content/supplementary/14784491-7-3-S3.doc]

\section{Additional file 4}

Evaluation of the content of each lesson of the "Evaluation 3.3 " module by the students of Cohort $1(n=17)$. Results of the evaluation by Cohort 1 of the content of each of each lesson of the evaluation lesson. Click here for file

[http://www.biomedcentral.com/content/supplementary/14784491-7-3-S4.doc]

\section{Additional file 5}

Mean differences among the 60 competences for the two cohorts. Mastery of the 60 competences by the end of the master's programme and a year later.

Click here for file

[http://www.biomedcentral.com/content/supplementary/14784491-7-3-S5.pdf]

\section{Acknowledgements}

We extend our heartfelt thanks to all the students for their participation in this study and their interest in programme evaluation. The assistance provided by Issa Sombié and Drissa Sia in data collection was also very much appreciated. The translation and the editing were done by Donna Riley. This programme is funded by the Bill and Melinda Gates Foundation. We also thank the referees for their useful comments to improve this paper.

\section{References}

I. Mills A, Bennett S, Russell S, Attanayake N: The challenge of health sector reform: what must governments do? Houndmills; New York: Palgrave; 2001.

2. OECD: Paris declaration on aid effectiveness. Ownership, Harmonisation, Alignment, Results and Mutual Accountability. Edited by DAC. Paris: DAC, OECD; 2005: I2.

3. Davis MV: Teaching practical public health evaluation methods. Am J Eval 2006, 27(2):247-256.

4. Varone F: Développer les capacités évaluatives: études pilotes au Congo, Niger et Sénégal. Paris: Organisation Internationale de la Francophonie; 2007:98.

5. Rouge J-C: The origin and development of the African evaluation guidelines. New Directions for Evaluation 2004, 104:55-66.

6. Banque Africaine de Développement: Suivi et Evaluation des Stratégies de Réduction de la Pauvreté dans les Pays Membres Régionaux: Evaluation des Besoins en Formation. Département de l'Evaluation des Opérations 2006:64.

7. Kedowide F-C: Étude d'identification des besoins et formulation d'un document de projet de renforcement des capacités de formation en matière d'évaluation. Ouagadougou: African Evaluation Association; 2006:72.

8. Milstein B, Chapel TJ, Wetterhall SF, Cotton DA: Building capacity for program evaluation at the Centers for Disease Control and Prevention. In The Art, Craft, and Science of Evaluation Capacity Building New Directions for Evaluation, $n^{\circ} 93$, spring 2002 Edited by: Stockdill SH, Baizerman M, Compton D. Wiley Periodicals, Inc; 2002:27-46.

9. Ridde V, Shakir S: Evaluation Capacity Building and Humanitarian Organization. Journal of MultiDisciplinary Evaluation 2005 , 3:78-II 12 .

10. Stockdill SH, Baizerman M, Compton D, (Eds): The art, craft and science of evaluation building Wiley Periodicals, Inc; 2002.

II. Rogers P, Gervais M: Le renforcement des capacités en évaluation. In Approches et pratiques de l'évaluation de programme Edited by: Ridde V, Dagenais C. Montréal: Presses de I'Université de Montréal; 2009:193-212.

12. Trevisan MS: Practical training in evaluation: a review of the litterature. Americal Journal of Evaluation 2004, 25(2):255-272.

13. Baya B, Laliberté D, Ridde V, Ouedraogo D, Piche V, Fournier P, Legrand T, Albert L, Sondo B: Le Master Population \& Santé de l'université de Ouagadougou: le défi d'une approche pédagogique innovante en Afrique sub-saharienne francophone. 24 e congrès de l'Association internationale de pédagogie universitaire. Montréal, Canada 2007.

14. Morgan CJ, Deutschmann PW: An evolving model for training and education in resource-poor settings: teaching health workers to fish. Med J Aust 2003, 178(I):2I-25.

15. Jackson SF, Ridde V, Valentini H, Gierman N: Canada's role in international health promotion. In Health Promotion in Canada: Critical perspectives 2nd edition. Edited by: O'Neill M, Pederson A, Rootman I, Dupéré S. Toronto: Canadian Scholars Press Inc; 2007:222-236.

16. Stevahn L, King JA, Ghere G, Minnema J: Evaluator competencies in university-based evaluation training programs. Canadian Journal of Program Evaluation 2005, 20(2): I0I-I 23.

17. Doré $G$, Marceau R: L'évaluation de programmes à la fonction publique québécoise un profil de compétences requises. Téléscope 2006:19-30. printemps - été

18. Lee J, Wallace TL, Alkin M: Using problem-based learning to train evaluators. Americal Journal of Evaluation 2007. 28(4):536-545.

19. Darabi A: Teaching Program Evaluation: Using a Systems Approach. Am J Eval 2002, 23(2):219-228. 
20. Patton MQ: Creative evaluation 2nd edition. Newbury Park, Beverly Hills, London, New Delhi: Sage Publications; 1987.

21. Preskill H, Russ-Eft D: Building evaluation capacity. 72 activities for teaching and training Thousand Oaks. London.: Sage publications; 2005.

22. Renger R, Titcomb A: A Three-Step Approach to Teaching Logic Models. Americal Journal of Evaluation 23(4):493-503.

23. Kirkpatrick DL: Evaluating training programs: the four levels Ist edition. San Francisco, Emeryville, CA: Berrett-Koehler; Publishers Group West [distributor]; 1994.

24. Stevahn L, King JA, Ghere G, Minnema J: Establishing Essential Competencies for Program Evaluators. Am J Eval 2005, 26(I):43-59.

25. Lam TCM, Bengo P: A comparison of three retrospective selfreporting methods of measuring chage in instructional practice. Am J Eval 2003, 24(I):65-80.

26. Pratt CC, McGuigan WM, Katzev AR: Measuring Program Outcomes: Using Retrospective Pretest Methodology. Am J Eval 2000, $21: 34$ I-349.

27. Amin ME: Six factors of course and teaching evaluation in a bilingual university on Central africa. Assessment \& Evaluation in Higher Education 2002, 27(3):28I-29l.

28. Van Dormael D, Dugas S, Kone Y, Coulibaly S, Sy M, Marchal B, Desplats D: Appropriate training and retention of community doctors in rural areas: a case study from Mali. Human Resources for Health 2008, 6(25): |478-449|.

29. Boutilier $M$, Mason $\mathrm{R}$ : The reflexive practionner in health promotion: from reflection to reflexivity. In Health Promotion in Canada: Critical perspectives 2nd edition. Edited by: O'Neill M, Pederson A, Rootman I, Dupéré S. Toronto: Canadian Scholars Press Inc; 2007:301-316.

Publish with Bio Med Central and every scientist can read your work free of charge

"BioMed Central will be the most significant development for disseminating the results of biomedical research in our lifetime. "

Sir Paul Nurse, Cancer Research UK

Your research papers will be:

- available free of charge to the entire biomedical community

- peer reviewed and published immediately upon acceptance

- cited in PubMed and archived on PubMed Central

- yours - you keep the copyright

Submit your manuscript here:

http://www.biomedcentral.com/info/publishing_adv.asp
BioMedcentral 